\title{
Endogenous ascorbic acid delays ethylene-induced leaf senescence in Arabidopsis thaliana
}

\author{
X.T. ZHENG ${ }^{\dagger}$, Z.C. YUं, X.F. CHEN, M.L. CAI, Y.Z. WANG, and C.L. PENG ${ }^{+}$ \\ Guangzhou Key Laboratory of Subtropical Biodiversity and Biomonitoring, Guangdong Provincial Key Laboratory \\ of Biotechnology for Plant Development, School of Life Sciences, South China Normal University, Guangzhou \\ 510631, China
}

\begin{abstract}
Leaf senescence is an important event in the plant life cycle. Ethylene and ascorbic acid (AsA) both regulate the leaf senescence process. The role of endogenous AsA in ethylene-induced leaf senescence was explored in two independent endogenous AsA changing Arabidopsis thaliana mutants. The line vtc2-1 with a single base change in VTC was AsAdeficient mutant; the GLDH-overexpressing line (GLDHOE) driven by the CaMV 35S promoter was AsA-overaccumulating mutant. After spraying $600 \mu \mathrm{M}$ ethephon for $6 \mathrm{~d}$, vtc2-1 showed the most serious leaf chlorosis, reactive oxygen species (ROS) accumulation, chlorophyll breakdown, Rubisco degradation, and had the highest expression level of senescenceassociated genes (SAGs), such as SAG12, SAG13, SAG20, and SAG21 among the three lines. In contrast, GLDHOE maintained the highest photosynthetic pigments contents, Rubisco content, antioxidant capacity, and the lowest expression of $S A G 2, S A G 20$, and $S A G 21$ among the three lines. Taken together, we conclude that endogenous AsA can delay ethyleneinduced senescence by scavenging ROS and inhibiting SAGs expression.
\end{abstract}

Additional key words: antioxidant; reduced ascorbic acid; senescent; vegetative organ.

\section{Introduction}

Senescence is the terminal stage of plant growth and development before death. Leopold (1961) described the term senescence as the process when plants showed decreased growth rates and vigor, increased susceptibility to challenge from pathogens or physical disturbance. Leaf is the main photosynthetic organ in plants and plays an eminently important role in plant development and biomass accumulation. Plant senescence, more specifically the leaf senescence, often comes with many physiological and biochemical changes, such as degradation of chlorophyll (Chl), decrease in photosynthetic capacity, accumulation of reactive oxygen species (ROS), and increase in malondialdehyde (MDA) content. Yoshida (2003) suggested that leaf senescence was a type of process programmed cell death (PCD), which was induced in an age-dependent manner and by various environmental factors. Leaf senescence is an oxidative process (Farouk 2011). The overproduction of superoxide anion $\left(\mathrm{O}_{2}{ }^{-}\right)$, singlet oxygen $\left({ }^{1} \mathrm{O}_{2}\right)$, hydroxyl radicals $\left({ }^{\circ} \mathrm{OH}^{-}\right)$, hydrogen peroxide $\left(\mathrm{H}_{2} \mathrm{O}_{2}\right)$ and other formation of ROS occurs dramatically during aging (Mencuccini and Munné-Bosch 2017). ROS are important signaling molecules, but the unbalance of production and elimination of ROS accelerates the process of leaf senescence. Antioxidant enzymes system and nonenzymatic antioxidants system have evolved to respond to oxidative stress (Alscher et al. 1997). The expression level of many genes changes in leaf senescence process. Some of them known as senescence-associated genes (SAGs) are upregulated, whereas some of them are termed senescence-downregulated genes (SDGs). Many SAGs are commonly used as molecular markers for leaf senescence (Hensel et al. 1993).

Leaf senescence is a complicated developmental process regulated and controlled by various cues, and

\footnotetext{
Received 12 November 2019, accepted 19 March 2020.

${ }^{+}$Corresponding author; e-mail: pengchl@scib.ac.cn

Abbreviations: ACC - 1-aminocyclopropane-1-carboxylate; ACO - ACC oxidase; ADH - alcohol dehydrogenase; AsA - ascorbic acid; Asc - reduced ascorbic acid; BSA - bovine serum albumin; DAB - diaminobenzidine; DPPH - 1,1-diphenyl-2-picrylhydrazyl; ET - ethylene; ETR 1 - ethylene responsive $1 ; \mathrm{F}_{\mathrm{O}}$ - minimal fluorescence yield of the dark-adapted state; $\mathrm{F}_{\mathrm{m}}-$ maximal fluorescence yield of the dark-adapted state; $F_{v} / F_{m}$ - maximal quantum yield of PSII photochemistry; GGPase - GDP-L-galactose phosphorylase; GLDH L-galactono-1,4-lactone dehydrogenase; LEA - late embryogenesis abundant protein; MDA - malondialdehyde; MS - Murashige and Skoog; NBT - nitroblue tetrazolium; ORE1 - ORESARA 1; PCD - process programmed cell death; PMSF - phenylmethylsulfonyl fluoride; ROS - reactive oxygen species; SAGs - senescence-associated genes; SDGs - senescence-downregulated genes; TCA trichloroacetic acid; TBA - thiobarbituric acid; WI12 - wound-induced protein 12.

Acknowledgments: This work was funded by the National Natural Science Foundation of China $(31870374,31570398)$. The study was also supported by Guangdong Province Natural Science Foundation (2017A030313167). Thanks to the vtc2-1 seed donated by Professor Patricia Müller-Moulé's laboratory and Professor Qingwei Meng's laboratory.

These authors contributed equally to this work.
} 
phytohormones are among the most vital ones (Khan et al. 2014). Some phytohormones advance leaf senescence [e.g., abscisic acid, ethylene (ET), jasmonic acid], whereas some inhibit this process (e.g., auxins, cytokinins, gibberellins) (Sarwat et al. 2013). Endogenous ET concentration in plants is positively correlated with leaf senescence. 1-aminocyclopropane-1-carboxylate (ACC) oxidase (ACO, EC 1.14.17.4) is the key enzyme in the ET biosynthesis pathway of higher plants (Ruduś et al. 2013). Transcript level for $A C O$ gene increased during the senescence process in tomato leaves (John et al. 1995). Picton et al. (1993) found that inhibiting tomato ACO activity reduced ET synthesis and finally delayed the leaf senescence. Life span of leaves of ET-insensitive mutants in Arabidopsis, err1 and ein2, was prolonged (Schaller and Bleecker 1995).

Similar to ET, ascorbic acid (AsA) content also affects leaf senescence (Farouk 2011). AsA is the water-soluble antioxidant molecule in plants. There is strong evidence that the AsA content and reductive state are positively correlated with plant resistance and negatively correlated with leaf senescence (Barth et al. 2004, 2006; Gallie 2012). Exogenous AsA supplement downregulates SAGs expression and slows down senescence in AsA-deficient mutants, vtc1 (Barth et al. 2004). GDP-L-galactose phosphorylase (GGPase, EC 2.7.7.69) and L-galactono1,4-lactone dehydrogenase $(\mathrm{GLDH}, \mathrm{EC}$ 1.3.2.3) are two key enzymes in the AsA biosynthesis pathway (Szarka et al. 2013). VTC2 is located on the $4^{\text {th }}$ chromosome and codes GGPase together with VTC5. GGPase converts GDP-L-galactose to 1-Gal-L-phosphate (Dowdle et al. 2007). GLDH directly oxidizes L-galactono-1,4-lactone (Gal) to L-ascorbic acid (Wheeler et al. 1998). GLDH gene coding GLDH locates on the $3^{\text {rd }}$ chromosome. Changing the expression levels of VTC2 and GLDH would directly affect the AsA synthesis. The line vtc2-1 had the mutation which changed the 3 ' splice site of the predicted intron 5 from AG to AA (Jander et al. 2002). Compared with WT, vtc2-1 showed lower AsA content, smaller rosette size, and earlier senescence (Dowdle et al. 2007, Kotchoni et al. 2009). Tabata et al. (2001) generated AsA-deficient transgenic tobacco AS1-1 and AS2-2 cell lines by antisense expression of the $G L D H$ and found that antisense suppression of GLDH mRNA led to a significant decline in the GLDH activity and a decrease in mitotic index. In contrast, Tokunaga et al. (2005) found that overexpression of $G L D H$ could increase AsA content in tobacco (Nicotiana tabacum L.).

At present, the oxidant scavenger role of AsA in alleviating developmental senescence or most of stressinduced senescence is well known (Terzi et al. 2015, Naz et al. 2016, Sade et al. 2017). In addition, senescence induced by various stresses shows significantly different regulation patterns (van der Graaff et al. 2006). ET could accelerate plant senescence (Sarwat et al. 2013). The role and specific mechanism of AsA in ET-induced senescence are still unknown. Does AsA also mainly play an antioxidant role in ET-induced senescence? Those questions all request further research to be answered.

In the following study, we constructed GLDH-over- expressing Arabidopsis thaliana. GLDH-overexpressing Arabidopsis, the AsA-deficient Arabidopsis (vtc2-1), and Arabidopsis ecotype Columbia (Col) were used to investigate the role of AsA in ET-induced senescence. Given ethephon is the common, efficient and convenient ET generator, we used ethephon in ET treatment. The different physiological, biochemical, and molecular responses of the three lines were analyzed. We hypothesized that (1) AsA regulated ET-induced senescence and (2) in addition to being an oxidant scavenger, AsA also played other roles in alleviating senescence.

\section{Materials and methods}

Construction of the $G L D H$-overexpressing Arabidopsis thaliana plant: Arabidopsis thaliana ecotype Columbia (Col) was used for constructing $G L D H$-overexpressing transgenic lines in this study. A full-length $G L D H$ (TAIR ID: AT3G47930) cDNA was amplified by RTPCR, and then cloned by using the specific primer pair: 5'-TCTCGAGATGCTCCGGTCACTTCT-3' and 5'-GGACTAGTTTAAGCAGTGGTGGAGACTG-3'. After the $G L D H$ fragment was introduced into a pMD18-T vector (Takara Co., Japan), the plasmid DNA harboring the full-length fragment of $G L D H$ and overexpression vector named $p$ CanGmyc were digested with XhoI and SpeI, ligated, and transferred into Escherichia coli (DH5 $\alpha$ ) competent cells. The constructed plasmid was transferred into Arabidopsis thaliana ecotype Col via the Agrobacterium-mediated floral dipping transformation method (Clough and Bent 1998). Homozygous transgenic line was obtained through the kanamycin-resistance test and quantitative RT-PCR analysis. The acquired $G L D H$ overexpressing line was named GLDHOE.

Plant materials, cultivation, and ET treatment: Seed of Arabidopsis ecotype Col was obtained from the Arabidopsis Biological Resource Center (ABRC). The $v t c 2-1$ mutant deficient in AsA was provided by Professor Patricia Müller-Moulé's Laboratory. After synchronizing at $4^{\circ} \mathrm{C}$ in dark for $3 \mathrm{~d}$, seeds of $\mathrm{Col}$ and $v t c 2-1$, as well as GLDHOE, were sown on sterilized Murashige and Skoog (MS) medium for $10 \mathrm{~d}$, and then transferred to soil (peat soil:vermiculite $=3: 1)$. Plants were grown under controlled conditions (PPFD of $100 \mu \mathrm{mol} \mathrm{m}{ }^{-2} \mathrm{~s}^{-1}, 16-\mathrm{h}$ light/8-h dark, $70-80 \%$ relative humidity, $20-22^{\circ} \mathrm{C}$ ).

For ET-induced aging treatment, 30-d-old plants were sprayed with $600 \mu \mathrm{M}$ ethephon twice per day (at 9:00 and 21:00 h). The other conditions were kept the same.

RNA extraction and gene expression analysis: Total RNA was extracted from leaves by using Column-type Plant Total RNA Extract Reagent Kit (Sangon Biotech., Shanghai, China) according to the manufacturer's instructions. The first cDNA was synthesized with the use of an oligo (dT) 18 primer and M-MLV reverse transcriptase (TaKaRa). The relative expression levels of ascorbic acid synthesisrelated enzyme genes ( $G L D H$ and $V T C 2)$ and senescenceassociated genes (SAG2,SAG12,SAG13,SAG20, and $S A G 21)$ were analyzed through an $A B I 7500$ Real-Time 
PCR System (Applied Biosystems, Foster City, USA) using the $S Y B R \circledast{ }^{\circledR}$ Premix EX Taq ${ }^{\mathrm{TM}}$ II (TaKaRa). Reaction mixture of $10 \mu \mathrm{L}$ consisted of $5 \mu \mathrm{L} 2 \times$ Premix Ex Taq II, $0.4 \mu \mathrm{L}$ of forward primer $(10 \mu \mathrm{M}), 0.4 \mu \mathrm{L}$ of reverse primer $(10 \mu \mathrm{M}), 0.2 \mu \mathrm{L}$ of $50 \times$ ROX reference dye, $0.5 \mu \mathrm{L}$ of cDNA template, and $3.5 \mu \mathrm{L}$ of $\mathrm{ddH}_{2} \mathrm{O}$. The reaction cycle consisted of $95^{\circ} \mathrm{C}$ for $30 \mathrm{~s}$, followed by 40 cycles $\left(95^{\circ} \mathrm{C}\right.$ for $5 \mathrm{~s}, 60^{\circ} \mathrm{C}$ for $34 \mathrm{~s}$ ), and then 1 cycle for recording a melt curve at $95^{\circ} \mathrm{C}$ for $15 \mathrm{~s}$ and $60^{\circ} \mathrm{C}$ for $1 \mathrm{~min}$. The relative transcript levels of genes were quantified relative to the tubulin $(T U B)$ gene and calculated by the $2^{-\Delta \Delta C}$ method (Livak and Schmittgen 2001). Primers used for qRT-PCR are listed in the text table below.

Ascorbic acid content assay: For determination of AsA and reduced ascorbic acid (Asc), $0.05 \mathrm{~g}$ of fresh rosette leaf samples were homogenized in $2 \mathrm{~mL}$ of $6 \%(\mathrm{w} / \mathrm{v})$ chilled trichloroacetic acid (TCA) solution and centrifuged at $13,000 \times g, 4^{\circ} \mathrm{C}, 5 \mathrm{~min}$. The supernatant was used for AsA and Asc content measurement as described by Gillespie and Ainsworth (2007). The absorbance at $525 \mathrm{~nm}$ was measured by the $U V-2450$ spectrophotometer (Shimadzu, Tokyo, Japan).

Chl pigment analysis: For $\mathrm{Chl}$ content analysis, fresh rosette leaf materials $(0.05 \mathrm{~g})$ were ground with liquid nitrogen in tubes, and extracted with $10 \mathrm{~mL}$ of chilled $80 \%$ acetone at $4^{\circ} \mathrm{C}$ in darkness for $24 \mathrm{~h}$. The absorption spectra of the Chl at 663,645 , and $470 \mathrm{~nm}$ wavelength were recorded using a $U V-2450$ spectrophotometer (Shimadzu, Tokyo, Japan). Contents of $\mathrm{Chl}$ and carotenoids were calculated by the method mentioned by Lichtenthaler (1987).

Chl fluorescence determination: One set of cut leaves was adapted to darkness for $20 \mathrm{~min}$ at the ambient temperature. A Chlorophyll Fluorescence Imaging System (CFImager, Technologica Ltd., Colchester, UK) was used to measure the minimum fluorescence, $F_{O}$, and the maximum fluorescence, $F_{m}$, under saturating pulse of
$6,162 \mu$ mol(photon) $\mathrm{m}^{-2} \mathrm{~s}^{-1}$. Maximal quantum yield of PSII photochemistry $\left(\mathrm{F}_{\mathrm{v}} / \mathrm{F}_{\mathrm{m}}\right.$, calculated as $\left.1-\mathrm{F}_{\mathrm{o}} / \mathrm{F}_{\mathrm{m}}\right)$ in the dark-adapted leaves represents the maximum efficiency of PSII (Oxborough and Baker 1997).

ROS localization by DAB and NBT staining: ROS localization was conducted following the procedure described by Romero-Puertas et al. (2004) with some modifications. $\mathrm{H}_{2} \mathrm{O}_{2}$ production was visualized by diaminobenzidine $(\mathrm{DAB})$ staining. Leaves in DAB staining solution [0.5 mg(DAB) $\mathrm{mL}^{-1}$ in $50 \mathrm{mM}$ potassium phosphate buffer ( $\mathrm{pH} 7.0)]$ were subjected to a vacuum for $10 \mathrm{~min}$ and incubated in darkness for $8 \mathrm{~h}$. After staining, leaves were boiled in $95 \%$ ethanol to remove Chl. Similarly, for $\mathrm{O}_{2}{ }^{--}$localization in situ, the leaves were immersed and vacuum-infiltrated in $50 \mathrm{mM}$ potassium phosphate buffer (pH 7.8) containing $0.1 \%$ nitroblue tetrazolium (NBT) and $10 \mathrm{mM}$ sodium azide for $10 \mathrm{~min}$. They were left in darkness for $3 \mathrm{~h}$ until the appearance of dark spots. The same decoloring procedure as with the DAB staining was done with the NBT staining. After DAB and NBT staining, the leaves were photographed by a digital camera (Canon, Eos-60D, Tokyo, Japan).

Soluble protein analysis: Rosette leaf samples $(0.1 \mathrm{~g})$ were homogenized in $2 \mathrm{~mL}$ of chilled extraction buffer containing $50 \mathrm{mM}$ Tris- $\mathrm{HCl}, 20 \mathrm{mM} \mathrm{MgCl}_{2}, 1 \mathrm{mM}$ EDTA$\mathrm{Na}_{2}, 10 \mathrm{mM} \beta$-mercaptoethanol, $10 \mathrm{mM}$ phenylmethylsulfonyl fluoride (PMSF) at $\mathrm{pH}$ 7.8. After centrifugation at $13,000 \times g$ and $4^{\circ} \mathrm{C}$ for $10 \mathrm{~min}, 0.25 \mathrm{~mL}$ of total soluble protein content in the supernatant was determined by the Bradford (1976) method, and bovine serum albumin (BSA) was used to construct the calibration curve. Ribulose1,5-bisphosphate carboxylase/oxygenase (Rubisco, EC 4.1.1.39) protein determination was estimated by SDSPAGE electrophoresis following the procedures described by Zhang et al. (2016). The electrophoresis was performed with a $4 \%$ stacking gel at $75 \mathrm{~V}$ for $30 \mathrm{~min}$ and a $12.5 \%$ separating gel at $110 \mathrm{~V}$ for $70 \mathrm{~min}$. After electrophoresis, the gel was stained with Coomassie Brilliant Blue, and the

\begin{tabular}{|c|c|c|}
\hline Gene ID & Gene name & Primer sequence \\
\hline AT5G62690 & $T U B$ & $\begin{array}{l}\text { Forward: 5'-CCAGCTTTGGTGATTTGAAC-3' } \\
\text { Reverse: 5'-AAGCTTTCGGAGGTCAGAG-3' }\end{array}$ \\
\hline AT3G47930 & $G L D H$ & $\begin{array}{l}\text { Forward: 5'-TTCTGGGCTTTGACTGTGG-3' } \\
\text { Reverse: 5'-GGTGCTGGTATTGCTTCCT-3' }\end{array}$ \\
\hline AT4G26850 & VTC2 & $\begin{array}{l}\text { Forward: 5'-TTCGCTATGATGTCACTGCCTG-3' } \\
\text { Reverse: 5'-GCAACGAAACCATACTTCCCC-3' }\end{array}$ \\
\hline AT5G60360 & $S A G 2$ & $\begin{array}{l}\text { Forward: 5'-CAGCAGCGGCTAATATCGG-3' } \\
\text { Reverse: 5'-TATCGGTGAGTGAAGCGAGC-3' }\end{array}$ \\
\hline AT5G45890 & SAG12 & $\begin{array}{l}\text { Forward: 5'-GGCGTTTTCAGCGGTTGCGG-3' } \\
\text { Reverse: 5'-CCGCCTTCGCAGCCAAAATGC-3' }\end{array}$ \\
\hline AT2G29350 & $S A G 13$ & $\begin{array}{l}\text { Forward: 5'-ATGACCGCTCTTGTCACTGG-3' } \\
\text { Reverse: 5'-AGCTGAGTTTCGTCTCTGGC-3' }\end{array}$ \\
\hline AT3G10985 & $S A G 20$ & $\begin{array}{l}\text { Forward: 5'-TCGGTAACGTTGTTGCTGGA-3' } \\
\text { Reverse: 5'-ACCAAACTCTTTCAAATCGCCA-3' }\end{array}$ \\
\hline AT4G02380 & $S A G 21$ & $\begin{array}{l}\text { Forward: 5'-TCTTCCGACGTGGTTATGCG-3' } \\
\text { Reverse: 5'-TGGGTTGATTCTTCCACTCCC-3' }\end{array}$ \\
\hline
\end{tabular}


large and small chain of Rubisco protein was identified by molecular mass (the large and small subunit have a molecular mass of 55 and $15 \mathrm{kDa}$, respectively). Then the gel was photographed by a digital camera (Canon, Eos$60 D$, Tokyo, Japan) to analyze the relative grey value of each band by TotalLab Quant software (Nonlinear Dynamics Ltd., Newcastle, UK).

Total antioxidative capability determination: Total antioxidative capability was measured using the DPPH (1,1-diphenyl-2-picrylhydrazyl) scavenging method as described by Peng et al. (2000). Fresh rosette leaf material $(0.05 \mathrm{~g})$ was homogenized in $2 \mathrm{~mL}$ of $50 \%$ ethanol and centrifuged at $4^{\circ} \mathrm{C}$ and $13,000 \times g$ for $10 \mathrm{~min}$. The absorbance at $517 \mathrm{~nm}$ of $2 \mathrm{~mL}$ of mixture containing $0.1 \mathrm{~mL}$ supernatant (or 50\% ethanol) and $1.9 \mathrm{~mL}$ freshly prepared $120 \mu \mathrm{M}$ DPPH (dissolved in 95\% methanol) was measured by the $U V-450$ spectrophotometer (Shimadzu, Tokyo, Japan) after standing for $20 \mathrm{~min}$. The amount of DPPH reductions was used to measure the antioxidative capability.

MDA determination: MDA content was determined by the method of Draper and Hadley (1990) with minor modification. Rosette leaf $(0.05 \mathrm{~g})$ was homogenized in $2 \mathrm{~mL}$ of chilled $10 \%(\mathrm{w} / \mathrm{v})$ TCA solution. After the homogenate centrifugation at $13,000 \times g$ for $10 \mathrm{~min}$, $1 \mathrm{~mL}$ of the supernatant was mixed with $1 \mathrm{~mL}$ of $0.67 \%$ $(\mathrm{w} / \mathrm{v})$ thiobarbituric acid (TBA) prepared in $10 \%(\mathrm{w} / \mathrm{v})$ TCA. The mixture was heated in boiling water for $15 \mathrm{~min}$, and then quickly cooled in an ice bath. Mixture was centrifuged at $13,000 \times g$ for $5 \mathrm{~min}$, and the absorbance of the supernatant was read at 600,532 , and $450 \mathrm{~nm}$ for calculation of MDA content ( $U V-2450$ spectrophotometer, Shimadzu, Tokyo, Japan).

Data analysis: Statistical analysis was performed using IBM SPSS Statistics 19.0 software (IBM, NY, USA). One-way analysis of variance (ANOVA) was performed at the 0.05 level using Duncan's post-hoc test. The data were graphed using SigmaPlot 12.5 software (Systat Software Inc., USA). All of the data are shown as the means \pm standard error (SE).

\section{Results}

Constructing and screening homozygous $G L D H$-overexpressing Arabidopsis thaliana: In order to gain the
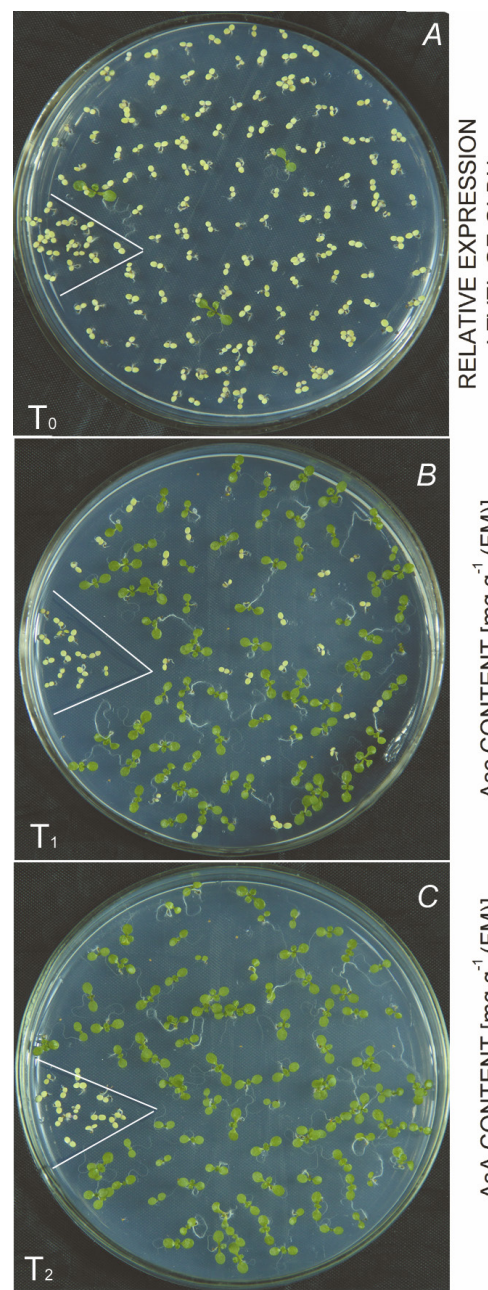

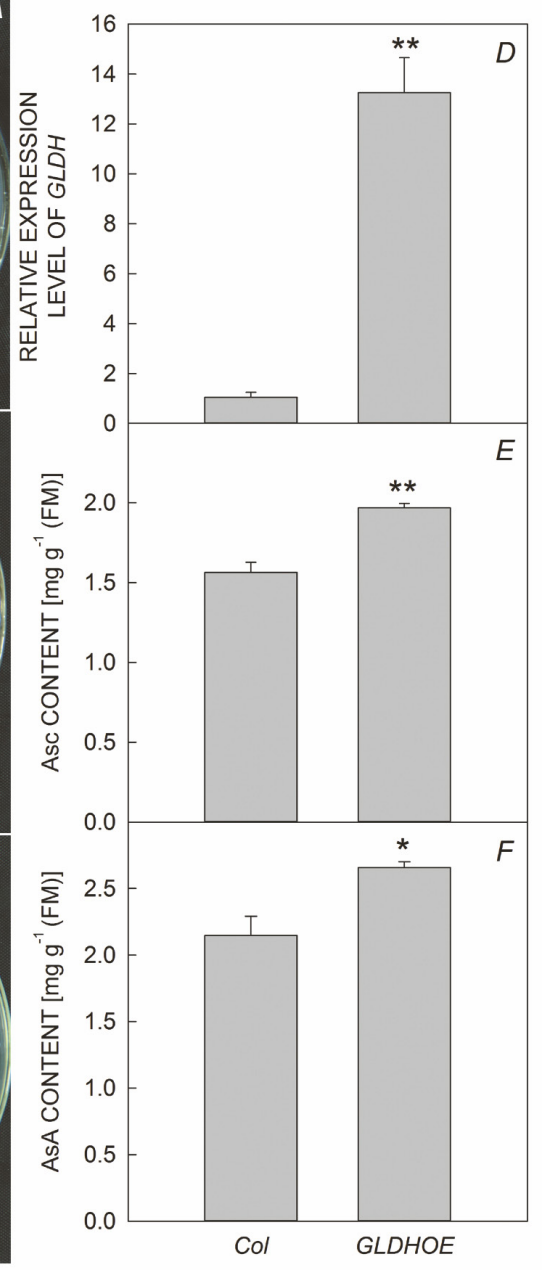

Fig. 1. Screening and identification of homozygous GLDH-overexpressing Arabidopsis thaliana. $(A-C)$ Transgenic Arabidopsis thaliana plants ( $p$ CanGmyc$G L D H)$ on $1 \times \mathrm{MS}+100 \mathrm{mg} \mathrm{L}^{-1}$ kanamycin culture medium plates. $(A) \mathrm{T}_{0}$ seeds in culture medium plate with $100 \mathrm{mg} \mathrm{L}^{-1}$ kanamycin. $(B) \mathrm{T}_{1}$ seeds in culture medium plate with $100 \mathrm{mg} \mathrm{L}^{-1}$ kanamycin. $\mathrm{T}_{1}$ seedlings showed 3:1 characters separation in MS medium with kanamycin. (C) Homozygous $\mathrm{T}_{2}$ seeds without characters separation in culture medium plate with kanamycin. $(D)$ Identification of $G L D H$ overexpressing line by qRT-PCR of $G L D H$ gene. $(E-F)$ Determination of the content of reduced ascorbic acid (Asc) $(E)$ and total ascorbic acid (AsA) $(F)$ in $G L D H$-overexpressing line. Data are means \pm SE $(n=4)$. The Student's $t$-test analysis indicates a significant difference (compared with the Col: $\left.{ }^{*} P<0.05 ;{ }^{* *} P<0.01\right)$. 
$G L D H$-overexpressing line, the Arabidopsis thaliana ecotype Col was transformed with a full-length $G L D H$ cDNA driven by the CaMV $35 \mathrm{~S}$ promoter. $\mathrm{T}_{0}$ seeds were harvested from Col after Agrobacterium-mediated floral dipping, and then were seeded in the kanamycin culture mediums to screen $\mathrm{T}_{0}$ successful transformation (Fig. 1A). $\mathrm{T}_{1}$ seed was harvested from surviving $\mathrm{T}_{0}$ and afterwards was grown in MS medium with kanamycin. The survival rate of $\mathrm{T}_{1}$ seedlings was $75 \%$, which showed that $G L D H$ was a single copy plasmid insertion (Fig. $1 B$ ). Homozygous $\mathrm{T}_{2}$ without segregation of character was gained from $\mathrm{T}_{1}$ (Fig. 1C). Finally, one homozygous $G L D H$-overexpressing line was obtained, which was named GLDHOE. The expression level of GLDH in GLDHOE was 13-fold as high as that of Col (Fig. 1D). Due to higher $G L D H$ expression level, the Asc and AsA content were significantly greater than that of $\mathrm{Col}$ (Fig. 1E,F).

Rosette leaf appearances after ethephon spraying: There were no obvious differences in the leaf appearances between Col, GLDHOE, and vtc2-1 grown under normal conditions until the $36^{\text {th }}$ day (Fig. 2; Fig. 1S, supplement). The line $v t c 2-1$ showed leaf chlorosis earliest, leaves of which became yellow on the $42^{\text {nd }}$ day. Col and GLDHOE had similar speed of leaf chlorosis (Fig. 1S). Some 30-d-old plants were treated by spraying $600 \mu \mathrm{M}$ ethephon. After 3-d treatment, some leaves of vtc2-1 showed leaf chlorosis
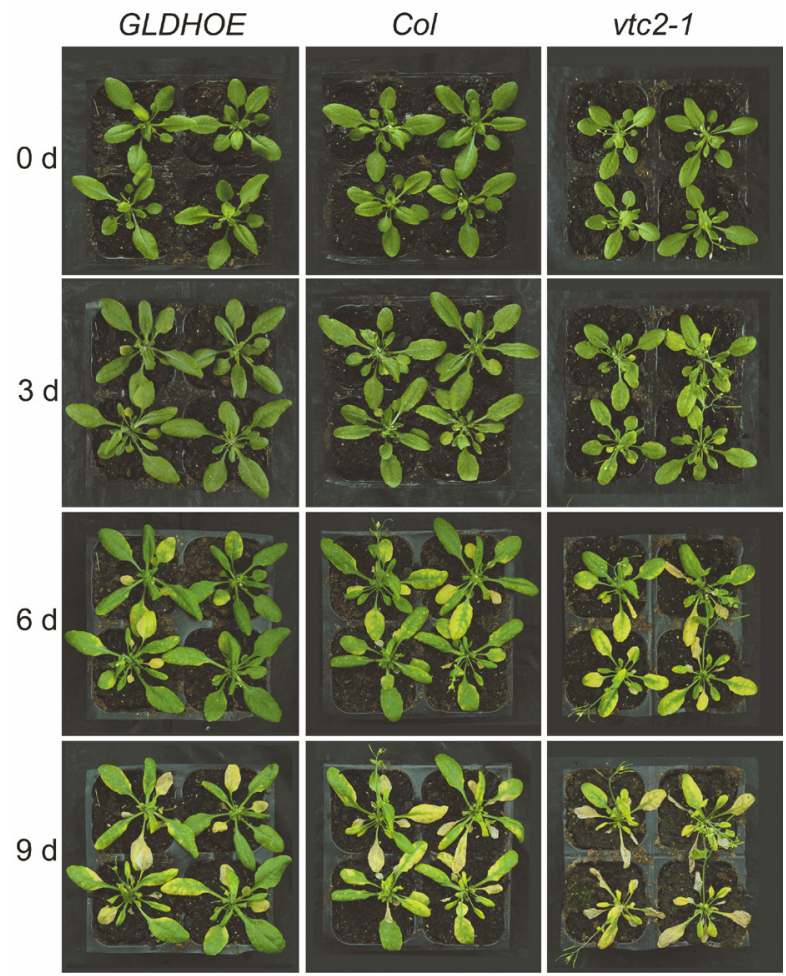

Fig. 2. Phenotype response of Arabidopsis to ethephon. Ethephon $(600 \mu \mathrm{M})$ was sustainedly sprayed on the leaves of the three Arabidopsis thaliana lines for 3, 6, $9 \mathrm{~d}$. GLDH-overexpressing line $(G L D H O E)$, ecotype Columbia $(\mathrm{Col})$, and VTC2-deficiency line (vtc2-1) are shown from left to right. first, while leaves of Col and GLDHOE did not turn yellow until the $6^{\text {th }}$ day of treatment. The GLDHOE had the least etiolated leaves after 6 d of ET treatment. After 9-d ET treatment, leaves of $v t c 2-1$ were almost withered and senescence necrotic, whereas the most leaves of GLDHOE still appeared green (Fig. 2). There have been obvious differences in leaf phenotypes between the three lines after 6-d ET treatment (i.e., the $36^{\text {th }}$ day of growth). Additionally, the three lines exhibited no obvious phenotypic differences after $36 \mathrm{~d}$ of natural growth and thus the effect of natural aging could be ignored. Thus, we chose to detect the biochemical and physiological parameters on the $6^{\text {th }}$ day of ET treatment.

AsA content upon ET treatment: After the ET treatment, the contents of Asc and AsA increased, especially the AsA content in GLDHOE. The GLDHOE line maintained the highest contents of AsA and Asc among the three lines either before or after treatment. In contrast, the Asc content of $v t c 2-1$ was the lowest one among the three lines (Fig. 3A,B). After 6-d ET treatment, the Asc/AsA contents in the three lines decreased, especially in $v t c 2-1$, which dipped to 0.65 (Fig. 3C). Here, we detected the expression levels of two key AsA-synthetic genes (GLDH, VTC2) in an effort to explain the reason for different AsA contents in the three lines. The results showed that the relative expression level of GLDH of GLDHOE, Col, and vtc2-1 increased 3.67, 3.16, and 1.10 times after 6-d ethephon spraying, respectively. The GLDH expression level was the highest in GLDHOE, followed by Col and then $v t c 2-1$, which was consistent with the AsA content (Fig. 3E). Unexpectedly, the expression level of VTC2 did not increase but significantly decreased after ET treatment, contrary to the trend of AsA content and GLDH expression level (Fig. 3D).

Photosynthetic pigments and Rubisco protein: Considering that the chloroplast is the main vulnerable site during various environmental stresses and natural senescence (Khanna-Chopra 2012), we compared the contents of photosynthetic pigments and Rubisco. After $6 \mathrm{~d}$ of ET treatment, the total $\mathrm{Chl}$ contents of leaves in GLDHOE, Col, and vtc2-1 declined by $34.8,61.5$, and $78.5 \%$, respectively. Either before or after treatments, GLDHOE had the significantly highest Chl content, followed by Col, and finally $v t c 2-1$, coinciding with leaf appearances (Figs. 2, 4C). The contents of $\mathrm{Chl} a, \mathrm{Chl} b$, and carotenoids showed a changing pattern very similar to the content of total Chl (Fig. $4 A-C, E$ ). After ethephon spraying, the ratio of Chl $a / b$ in $v t c 2-1$ decreased by $17.6 \%$, which was the greatest decline among the three lines. The $\mathrm{Chl} a / b$ ratio of $v t c 2-1$ was also slightly lower than that of $\mathrm{Col}$ and GLDHOE, though the difference was not statistically significant (Fig. 4D).

SDS-PAGE analysis (Fig. 5A) demonstrated that lower Rubisco was accumulated in three lines after 6-d ET treatment. The data showed that there were no significant differences between the three lines in Rubisco protein content before ethephon spraying. After 6-d treatment, the contents of Rubisco large subunit, Rubisco small subunit, 


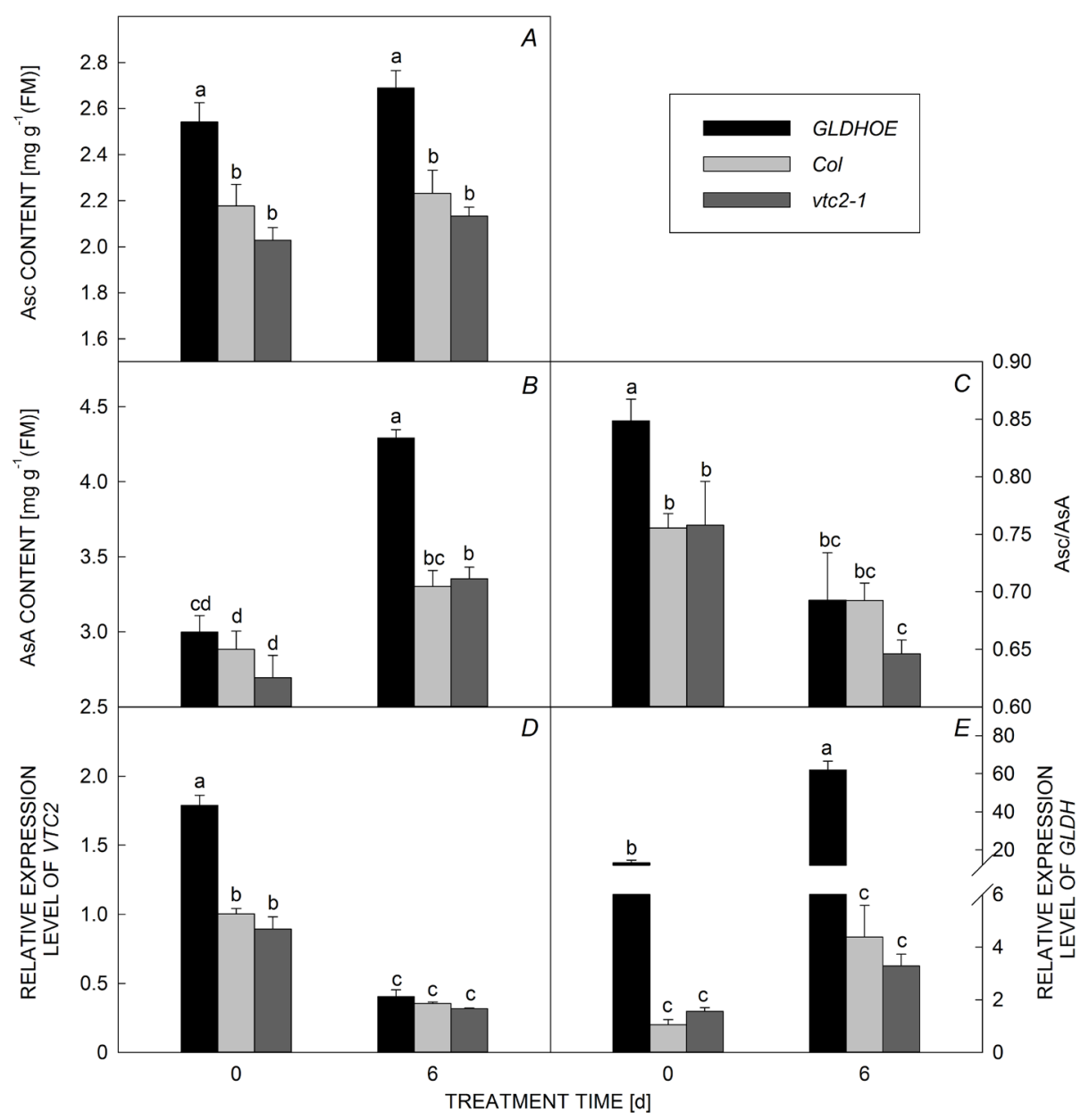

Fig. 3. Change of the contents of reduced ascorbic acid (Asc) $(A)$, total ascorbic acid (AsA) $(B)$, and reduced ascorbic acid/ascorbic acid ratio (Asc/AsA) $(C)$ as well as the relative expression levels of two key AsA biosynthetic genes - VTC2 $(E)$ and $G L D H(D)$ in rosette leaves of Arabidopsis thaliana (GLDHOE, Col, vtc2-1) before and after ET (600 $\mu \mathrm{M}$ ethephon) treatment. Data are means $\pm \mathrm{SE}(n=5)$. Different letters above bars indicate statistical significance $(P<0.05)$.

Rubisco, and soluble proteins in $v t c 2-1$ sharply decreased by $92.4,96.2,93.9$, and $54.1 \%$, respectively (Fig. $5 B-E$ ), which was the highest reduction among the three lines. The Rubisco and soluble protein content of $\mathrm{Col}$ and GLDHOE just slightly decreased after ethephon spraying and no significant difference was found before and after treatment.

Given the different lower content of Chl after ethephon spraying, the maximum PSII quantum yield $\left(\mathrm{F}_{\mathrm{v}} / \mathrm{F}_{\mathrm{m}}\right)$ was measured in leaves of GLDHOE, Col and $v t c 2-1 . \mathrm{F}_{\mathrm{v}} / \mathrm{F}_{\mathrm{m}}$ in the leaves of $v t c 2-1$ and $\mathrm{Col}$ significantly decreased after ET treatment, especially in AsA-deficient mutant vtc2-1. In contrast, the $\mathrm{F}_{\mathrm{v}} / \mathrm{F}_{\mathrm{m}}$ value of GLDHOE was greater than that of the other two and was comparable before and after treatment (Fig. 5F).

Localization of ROS in tissues upon ET treatment: Using DAB histochemical staining, we detected the least $\mathrm{H}_{2} \mathrm{O}_{2}$ accumulated in the leaves of $\mathrm{G} L D H O E$, followed by Col, and finally $v t c 2-1$ (Fig. $6 A$ ). The corresponding accumulation of greatest amounts of $\mathrm{H}_{2} \mathrm{O}_{2}$ was in the vtc2-1 mutant with the lowest content of AsA among the three lines after 6-d ET treatment (Figs. 3B, 6A). However, in superoxide radical detection, where the blue formazan deposits were characteristic of reaction of NBT with $\mathrm{O}_{2}{ }^{--}$, the results showed that there were no significant differences between the three lines (Fig. 6A).

Total antioxidant capacity and MDA content: Given the different $\mathrm{H}_{2} \mathrm{O}_{2}$ accumulation in the three lines, we determined the total antioxidant capacity and the MDA content of the lines. Before ethephon spraying, the three lines had similar antioxidant capacity. But antioxidant capacity of $\mathrm{Col}$ and $v t c 2-1$ decreased significantly after ethephon spraying, especially in vtc2-1 (Fig. 6B). Total antioxidant capacity of GLDHOE remained higher than that of the other two lines, and was comparable before and after treatment. Coincidently with the results of $\mathrm{H}_{2} \mathrm{O}_{2}$ accumulation, MDA concentration as a measure of membrane integrity was similar and low in all three lines before ET treatment, but significantly increased after ET treatment. MDA content was significantly lower in 
GLDHOE compared to the other two (Fig. 6C).

Relative expression of senescence-associated genes: We compared the expression levels of SAGs, which are believed to be useful molecular markers for leaf senescence, among the three lines during ET-induced aging process (Hensel et al. 1993, Wojciechowska et al. 2018). The results showed that the expression of $S A G 2$, $S A G 12, S A G 13, S A G 20, S A G 21$ were all at low level and there were no significant differences between them before ethephon spraying. After ethephon spraying, the expression of five tested genes drastically increased, especially $S A G 12, S A G 13$, and $S A G 20$. Among the three lines, vtc2-1 had the highest expression level of $S A G 12$, $S A G 13, S A G 20, S A G 21$, which were 125.2, 2.4, 1.2, 2.9 times higher than in Col, whereas GLDHOE had the lowest expression level of $S A G 2, S A G 20$, and $S A G 21$, which were 3.5, 2.6, 1.2 times lower than in Col (Fig. 7).

\section{Discussion}

In this study, we constructed a $G L D H$-overexpressing Arabidopsis thaliana driven by the CaMV $35 \mathrm{~S}$ promoter and named it GLDHOE. The GLDH expression level of GLDHOE was about 13 times higher than that of Col. GLDHOE and Col, as well as vtc2-1, the VTC2 mutant with single nucleotide mutations, were selected to undergo the ET treatment by $600 \mu \mathrm{M}$ ethephon spraying. The different physiological, biochemical, and molecular responses of three lines to ET treatment were analyzed to explore the function of AsA in ET-induced leaf senescence.

AsA delayed ET-induced leaf senescence: Previous work has proved that changing the expression of $G L D H$ or VTC2 could alter the AsA content in plants (Tokunaga et al. 2005, Kotchoni et al. 2009). Among the three lines, GLDHOE accumulated the highest AsA and Asc content due to overexpressing $G L D H$, whereas $v t c 2-1$ had the lowest AsA and Asc content because of downregulated expression of $V T C 2$ (Fig. $3 A, B$ ). Interestingly, qRT-PCR showed that the expression of $V T C 2$ was upregulated in the GLDHOE plants. On the one hand, VTC2 and GLDH encoded two key enzymes in the AsA biosynthesis pathway, GGPase and GLDH, respectively (Szarka et al. 2013). Some evidence had suggested that overexpression of one gene might trigger the expression of other genes in

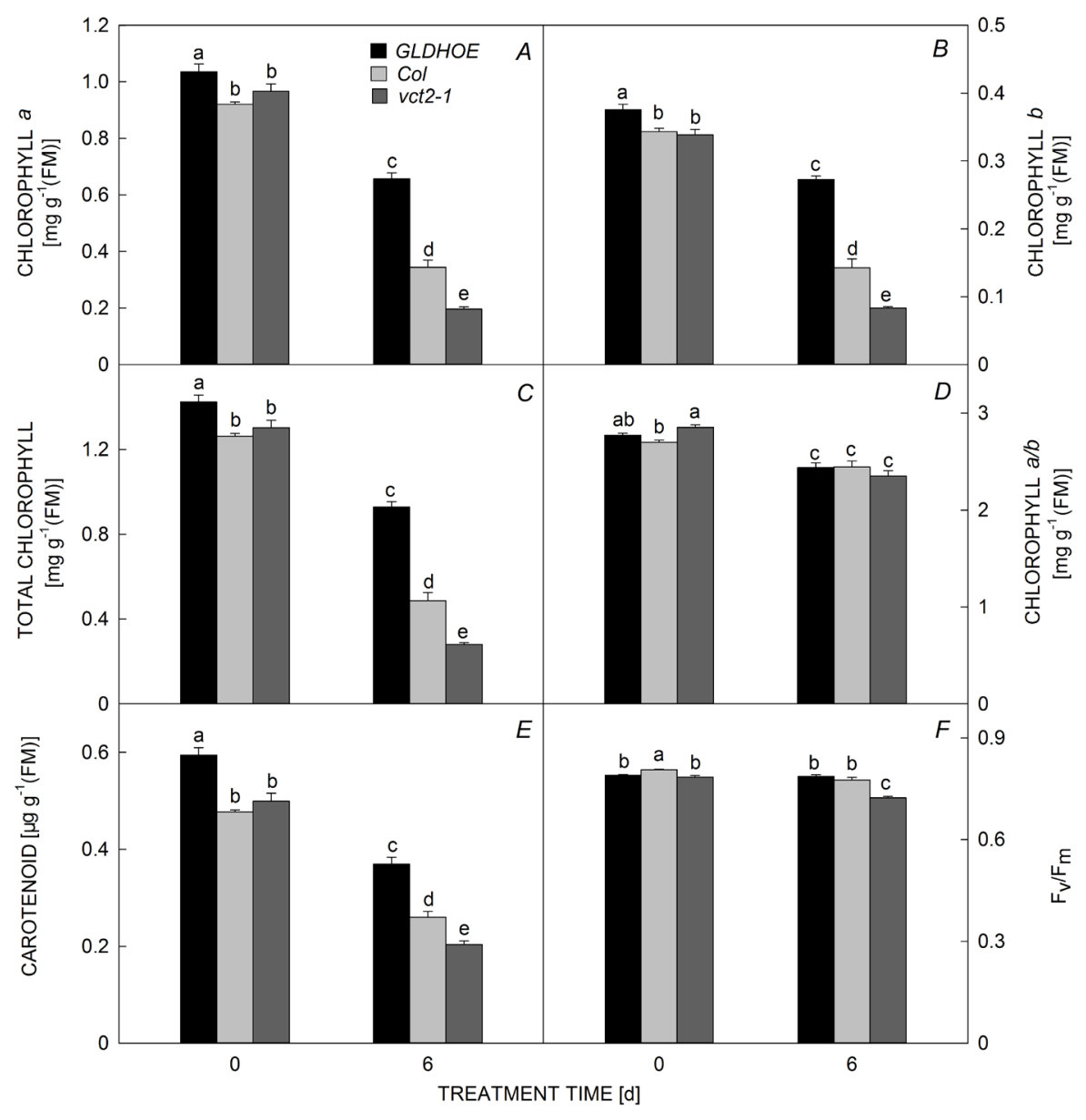

Fig. 4. Chlorophyll (Chl) $a$ content $(A), \mathrm{Chl} b$ content $(B)$, total Chl content $(C)$, Chl $a / b(D)$, carotenoid content $(E)$, and maximum efficiency of PSII photochemistry $\left(\mathrm{F}_{\mathrm{v}} / \mathrm{F}_{\mathrm{m}}\right)(F)$ in rosette leaves of Arabidopsis thaliana (GLDHOE, Col, vtc2-1) before and after ET $(600 \mu \mathrm{M}$ ethephon) treatment. Data are means $\pm \mathrm{SE}(n=5)$. Different letters above bars indicate statistical significance $(P<0.05)$. 

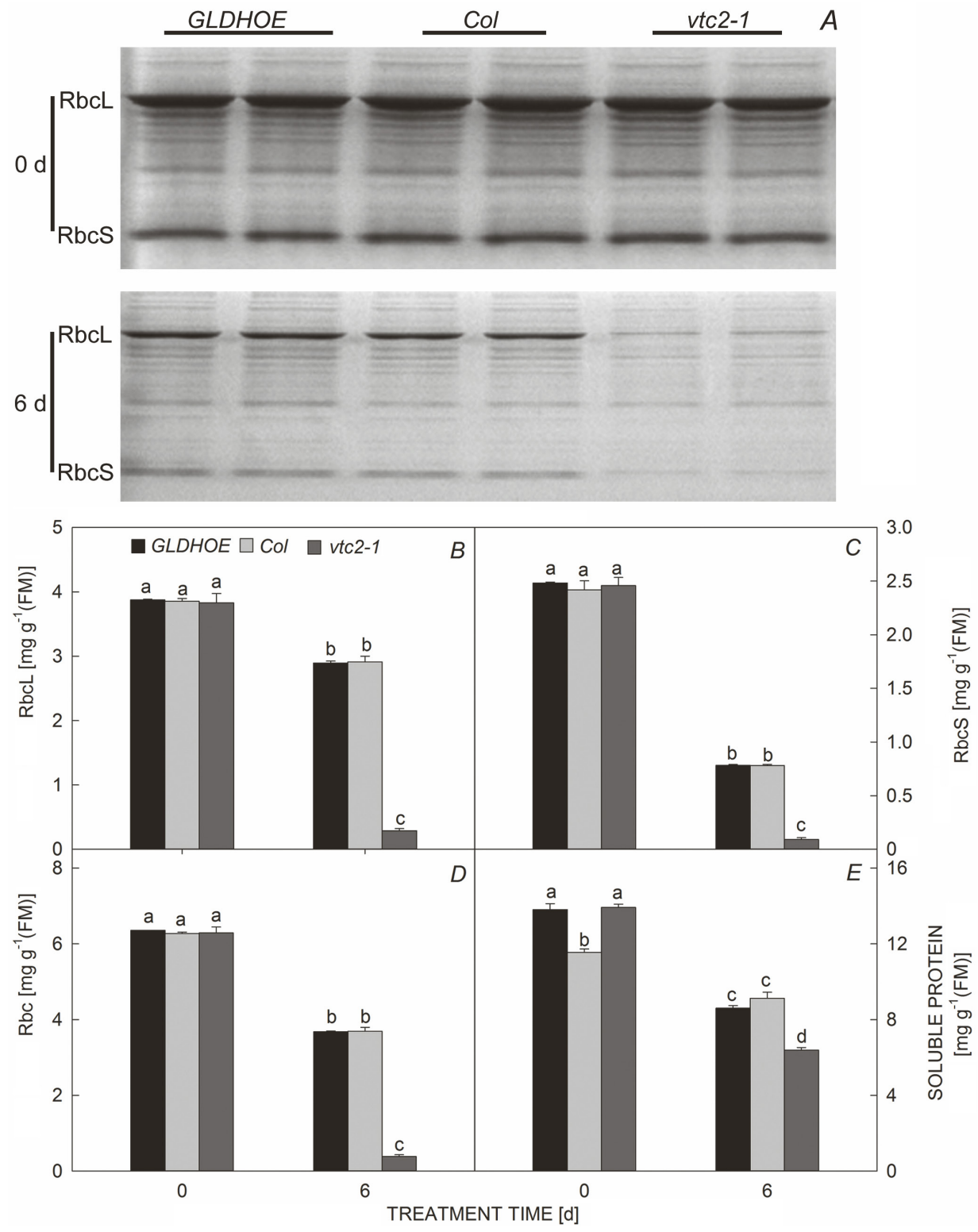

Fig. 5. Decrease in Rubisco content in rosette leaves of Arabidopsis thaliana (GLDHOE, Col, vtc2-1) after ET (600 $\mu \mathrm{M}$ ethephon) treatment. $(A)$ Rubisco large subunit (RbcL, $55 \mathrm{kDa}$ ) and small subunit (RbcS, $15 \mathrm{kDa}$ ) were separated by $12.5 \%$ SDS-PAGE. The loading samples of SDS-PAGE gel were soluble proteins. $(B-E) \mathrm{RbcL}$ content $(B)$, RbcS content $(C)$, total Rubisco content $(\mathrm{Rbc})(D)$, and soluble protein content $(E)$ in rosette leaves of three Arabidopsis lines before and after 6-day of ET ( $600 \mu \mathrm{M}$ ethephon) treatment. Data are means \pm SE $(n=5)$. Different letters above bars indicate statistical significance $(P<0.05)$.

the same synthetic pathway (Luo et al. 2016, Zhang et al. 2018). On the other hand, in addition to AsA synthesis, GLDH also involved the accumulation of mitochondrial NADH-ubiquinone oxidoreductase (complex I) which was the largest enzyme of the oxidative phosphorylation system (Pineau et al. 2008). Triggers, which modulate respiration, also impact AsA production, in which VTC2 participates (Millar et al. 2003). Upregulation of $G L D H$ expression might have indirectly affected VTC2 expression via respiration. After 6-d ethephon spraying, AsA and Asc content significantly increased in the three lines. GLDHOE still had the highest AsA and Asc content among the three lines and Asc content of vtc2-1 was still the lowest one (Fig. $3 A, B$ ). qRT-PCR results showed that after ET treatment, the expression levels of $G L D H$ were significantly upregulated in the three lines, whereas $V T C 2$ expression levels were all downregulated. The results seemed to imply that ET mainly induced AsA synthesis by upregulating the expression of $G L D H$, but not VTC2. However, Yu et al (2019) identified VTC2 as the direct target of ET in the regulation of AsA biosynthesis and ROS accumulation. The mechanisms of ET in the regulation of AsA biosynthesis remain poorly understood, which might be affected by the content of ET. What is 
more, as previously mentioned, $G L D H$ also involved the accumulation of complex I, the largest enzyme of the oxidative phosphorylation system (Pineau et al. 2008). Respiration rate tends to increase during the period of senescence (Kan et al. 2011). Mitochondria remain intact until late in the senescence process in order to continue respiration (Smart 1994). However, ET could inhibit AsA synthesis (Caviglia et al. 2018). Thus, the balance between respiratory demand and ET inhibition may be the reason why the expression of $G L D H$ was upregulated whereas VTC2 was downregulated.

At the same time, we also observed that during the process of ET-induced senescence, the leaf chlorosis appeared earliest and most seriously in vtc2-1, followed by Col, and finally GLDHOE (Fig. 2). Leaf yellowing was previously reported to be the most significant manifestation of leaf senescence (Ougham et al. 2008). The chloroplast is the main vulnerable site during stress and senescence, and the Chl breakdown is considered to be the common feature of leaf senescence induced by different factors (Kan et al. 2011, Woo et al. 2018). Both Chl and Rubisco contents decreased significantly after ET treatment, and the $v t c 2-1$ showed the most severe symptoms (Figs. 4, 5). Chl breakdown directly lowered the efficiency of PSII (Mencuccini and Munné-Bosch 2017). Thus, $F_{v} / F_{m}$ ratio showed the similar changing pattern with the contents of Chl (Figs. 4, 5). In addition, cell membrane of GLDHOE had minimal damage among the three lines upon ET treatment, as reflected by the lowest increase in cell membrane leakage and MDA content. Taking these data together, compared to Col, vtc2-1 with less AsA was highly susceptible to the senescence mediated by ethephon, whereas the GLDHOE with higher AsA content showed the delay in ET-induced aging. The decreasing or increasing of the AsA concentration might accelerate or delay the natural aging process, which has been proposed by previous research (Barth et al. 2006, Kotchoni et al. 2009). Changes in endogenous AsA content also affected the ET-induced aging process.

AsA alleviated the damage of ROS: ROS are unavoidable byproducts of cellular metabolism (Xu et al. 2017). Plants produce more ROS during aging process (Wojciechowska et al. 2018). If the balance of ROS generation and scavenging is destroyed, excess ROS would attack cell components, such as chloroplasts and cell membrane. This might promote leaf senescence. ROS are also the important signaling molecules accelerating aging process by promoting SAGs gene expression (John et al. 2001, Navabpour et al. 2003). AsA was known as a powerful antioxidant in plants (Noctor and Foyer 1998). Thus, the GLDHOE had the highest antioxidant capacity due to its highest AsA content, followed by Col and then vtc2-1. The DAB-staining results showed that mutants with VTC2 downregulated expression accumulated more $\mathrm{H}_{2} \mathrm{O}_{2}$ than did the Col and GLDHOE after 6-d ET treatment (Fig. 6A). This result indicates that the vtc2-1 suffered more seriously by oxidative stress under ET treatment than did the other two. Also, the highest AsA content and antioxidant capacity scavenging most ROS might be the
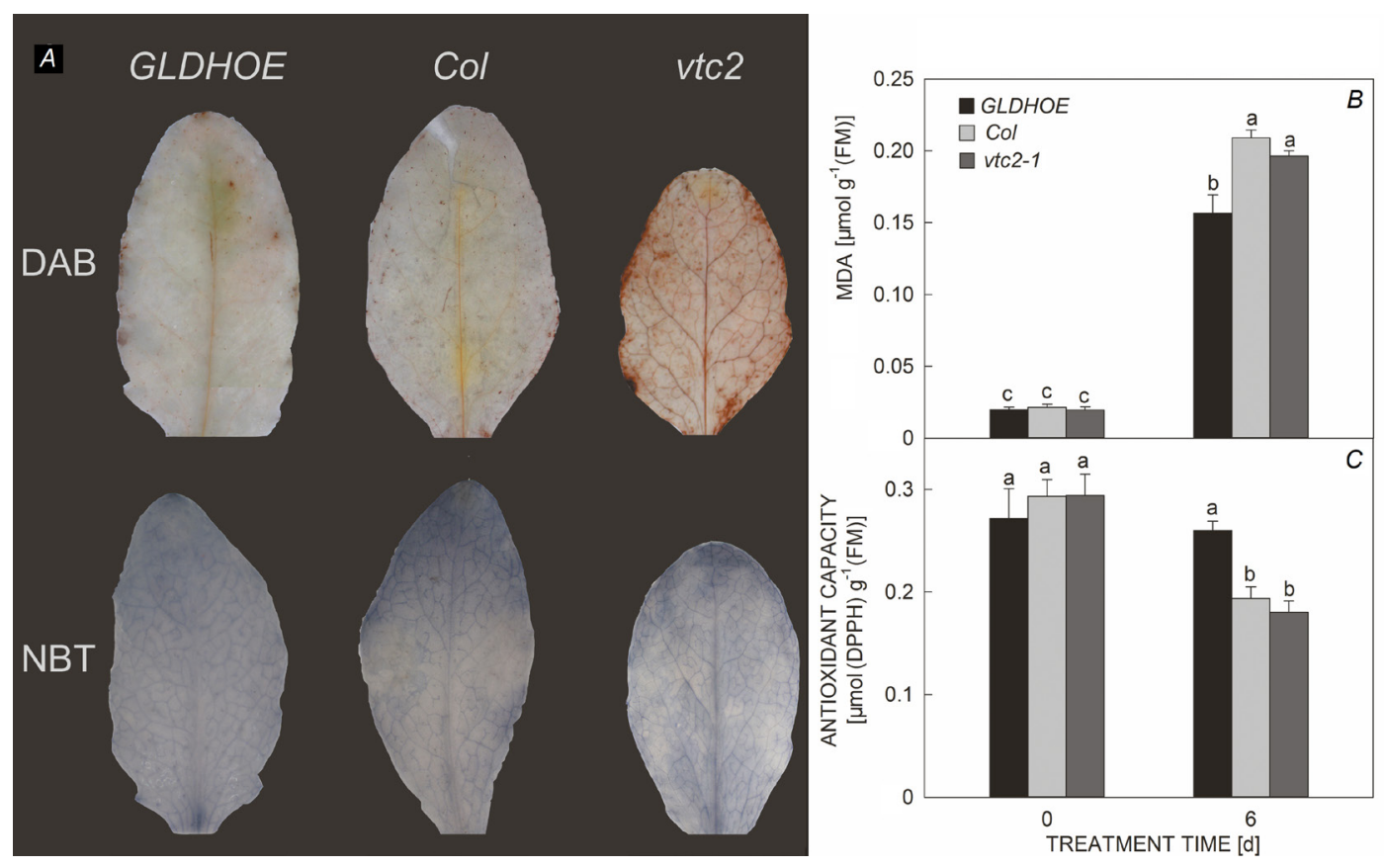

Fig. 6. Diaminobenzidine (DAB) and nitroblue tetrazolium (NBT) staining (A) in leaves of Arabidopsis thaliana (GLDHOE, Col, $v t c 2-1)$ after ET (600 $\mu \mathrm{M}$ ethephon) treatment. Antioxidant capacity $(B)$ and malondialdehyde (MDA) content $(C)$ in rosette leaves of three lines before and after $6 \mathrm{~d}$ of ET $(600 \mu \mathrm{M}$ ethephon) treatment. Data are means $\pm \mathrm{SE}(n=5)$. Different letters above bars indicate statistical significance $(P<0.05)$. 


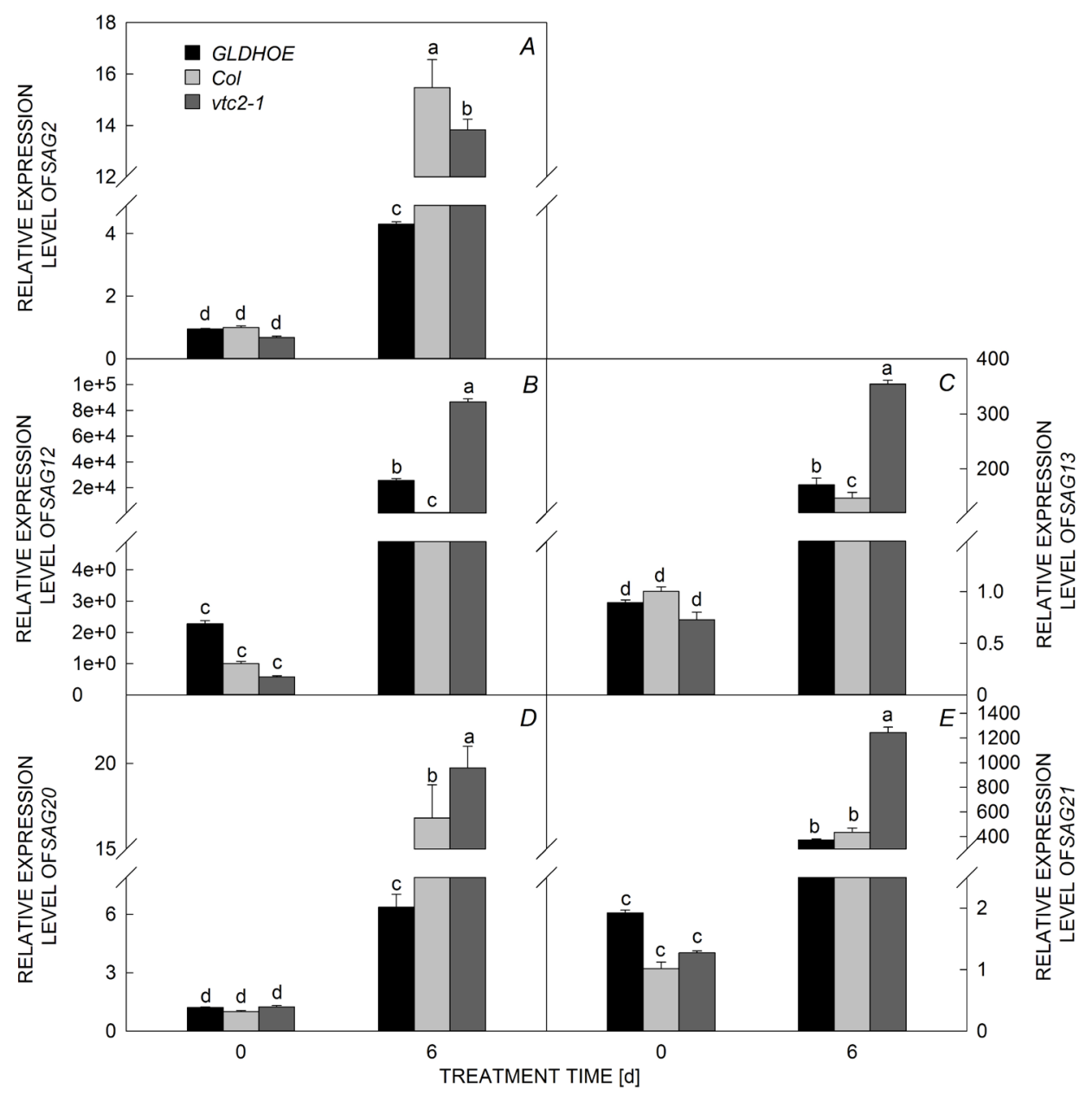

Fig. 7. Relative expression level of SAG2 (A), SAG12 (B), SAG13 (C), SAG20 (D), and SAG21 (E) in rosette leaves of Arabidopsis thaliana (GLDHOE, Col, vtc2-1) before and after ET (600 $\mu \mathrm{M}$ ethephon) treatment. Data are means $\pm \mathrm{SE}(n=4)$. Different letters above bars indicate statistical significance $(P<0.05)$.

reason why SAGs expression level of GLDHOE was the lowest among the three lines (Fig. 7).

Crosstalk between AsA and SAGs upon ET treatment: Upon ET treatment, the ET receptors ETR1 (ET RESPONSIVE 1) and homologous proteins are bound with ET, and then initiate ET signaling. Next, the transcription of the transcription factor ORE1 (ORESARA 1) is enhanced, which finally regulates the expression of a large set of SAG family (Kim et al. 2009, Khan et al. 2014). As in previous reports, ET increased the expression of SAG genes, including SAG2, SAG12, SAG13, SAG20, and SAG21 (Fig. 7) (Weaver et al. 1998, Grbić 2003). AsA content seemed to regulate the expression level of SAGs under ET treatment. AsA-deficient mutant, $v t c 2-1$, intensified the increase in the expression of $S A G 12, S A G 13, S A G 20$, and $S A G 21$, whereas AsA-overaccumulating mutant slowed down the increase in the expression of $S A G 2, S A G 20$, and $S A G 21$ (Fig. 7). $S A G 2$ and $S A G 12$ encode cysteine proteases (EC 3.4.22), which are key enzymes for degradation of large subunit of Rubisco, increasing under stress (Hensel et al. 1993, Lohman et al. 1994, Khanna-
Chopra et al. 1999). SDS-PAGE results showed that large subunit of Rubisco content declined most severely in $v t c 2-1$ with less AsA, showing the similar trend pattern of $S A G 2$ and $S A G 12$ expression. SAG13 encodes alcohol dehydrogenase (ADH, EC 1.1.1.1.), which plays an important role in plant response to both abiotic and biotic stresses (Shi et al. 2017). ET increased ADH activity and the SAG13 expression and vice versa (Manríquez et al. 2006, González-Agüero et al. 2009, Singh et al. 2010). The coding protein of $S A G 20$ is wound-induced protein 12 (WI12) (Weaver et al. 1998). Stanford et al. (1989) found two novel wound-induced genes, win1 and win2, from wound of potato tubers, showing striking homologies to chitin-binding proteins. Late embryogenesis abundant protein (LEA), coded by $S A G 21$, was found in vegetative plant tissues following environmental stress (Ingram and Bartels 1996, Hundertmark and Hincha 2008). The upexpression of $\mathrm{ADH}, \mathrm{WI12}$, and LEA also meant that the plant was facing stress or senescence. The line $v t c 2-1$ with the least AsA showed the highest SAGs expression level, meaning the greatest ET impact on senescence in $v t c 2-1$ among the three lines. That implied that AsA 
might regulate signal pathway of ET-induced senescence. As mentioned above, antioxidant capacity of AsA could alleviate the further aggravation of aging by ROS. Indeed, there was a negative correlation between AsA content and the accumulation of longer-lived ROS, such as $\mathrm{H}_{2} \mathrm{O}_{2}$, but without significant difference of short-lived ROS, such as $\mathrm{O}_{2}{ }^{--}$, in the three lines with different content of AsA. Thus, the amount of ROS could partially explain the different expression levels of SAGs among the three lines, but not completely (Figs. 6, 7). There might be other possible SAGs signaling transduction pathways mediated by AsA, which does not depend on the regulatory pathways of ROS scavenging. Furthermore, a recent research showed that encoding genes involved in ET biosynthesis and signaling were inhibited by AsA by a RNA-seq analysis (Caviglia et al. 2018). That implied that AsA also could regulate endogenous ET to affect SAGs expression in ET-induced senescence.

In summary, endogenous AsA can alleviate ET-induced senescence. First, AsA scavenges ROS due to its antioxidant characteristic, and thus decreases the expression of SAGs and degradation of cell components stimulated by ROS. In addition, AsA can partially inhibit SAGs expression independent of ROS scavenging pathway.

\section{References}

Alscher R.G., Donahue J.L., Cramer C.L.: Reactive oxygen species and antioxidants: Relationships in green cells. Physiol. Plantarum 100: 224-233, 1997.

Barth C., De Tullio M., Conklin P.L.: The role of ascorbic acid in the control of flowering time and the onset of senescence. J. Exp. Bot. 57: 1657-1665, 2006.

Barth C., Moeder W., Klessig D.F., Conklin P.L.: The timing of senescence and response to pathogens is altered in the ascorbate-deficient Arabidopsis mutant vitamin c-1. - Plant Physiol. 134: 1784-1792, 2004.

Bradford M.M.: A rapid and sensitive method for the quantitation of microgram quantities of protein utilizing the principle of protein-dye binding. - Anal. Biochem. 72: 248-254, 1976.

Caviglia M., Morales L.M.M., Concellón A. et al.: Ethylene signaling triggered by low concentrations of ascorbic acid regulates biomass accumulation in Arabidopsis thaliana. Free Radical Bio. Med. 122: 130-136, 2018.

Clough S.J., Bent A.F.: Floral dip: a simplified method for Agrobacterium-mediated transformation of Arabidopsis thaliana. - Plant J. 16: 735-743, 1998.

Dowdle J., Ishikawa T., Gatzek S. et al.: Two genes in Arabidopsis thaliana encoding GDP-l-galactose phosphorylase are required for ascorbate biosynthesis and seedling viability. Plant J. 52: 673-689, 2007.

Draper H.H., Hadley M.: Malondialdehyde determination as index of lipid peroxidation. - Method. Enzymol. 186: 421431, 1990.

Farouk S.: Ascorbic acid and $\alpha$-tocopherol minimize salt-induced wheat leaf senescence. - J. Stress Physiol. Biochem. 7: 58-79, 2011.

Gallie D.R.: The role of L-ascorbic acid recycling in responding to environmental stress and in promoting plant growth. J. Exp. Bot. 64: 433-443, 2012

Gillespie K.M., Ainsworth E.A.: Measurement of reduced, oxidized and total ascorbate content in plants. - Nat. Protoc. 2: 871-874, 2007.
González-Agüero M., Troncoso S., Gudenschwager O. et al.: Differential expression levels of aroma-related genes during ripening of apricot (Prunus armeniaca L.). - Plant Physiol. Bioch. 47: 435-440, 2009.

Grbić V.: SAG2 and SAG12 protein expression in senescing Arabidopsis plants. - Physiol. Plantarum 119: 263-269, 2003.

Hensel L.L., Grbić V., Baumgarten D.A., Bleecker A.B.: Developmental and age-related processes that influence the longevity and senescence of photosynthetic tissues in Arabidopsis. - Plant Cell 5: 553-564, 1993.

Hundertmark M., Hincha D.K.: Lea (late embryogenesis abundant) proteins and their encoding genes in Arabidopsis thaliana. - BMC Genomics 9: 118, 2008.

Ingram J., Bartels D.: The molecular basis of dehydration tolerance in plants. - Annu. Rev. Plant Biol. 47: 377-403, 1996.

Jander G., Norris S.R., Rounsley S.D. et al.: Arabidopsis mapbased cloning in the post-genome era. - Plant Physiol. 129: 440-450, 2002.

John C.F., Morris K., Jordan B.R. et al.: Ultraviolet-B exposure leads to up-regulation of senescence-associated genes in Arabidopsis thaliana. - J. Exp. Bot. 52: 1367-1373, 2001.

John I., Drake R., Farrell A. et al.: Delayed leaf senescence in ethylene-deficient ACC-oxidase antisense tomato plants: molecular and physiological analysis. - Plant J. 7: 483-490, 1995.

Kan J., Wang H.M., Jin C.H. et al.: Changes of reactive oxygen species and related enzymes in mitochondria respiratory metabolism during the ripening of peach fruit. - Agr. Sci. China 10: 149-158, 2011.

Khan M., Rozhon W., Poppenberger B.: The role of hormones in the aging of plants - a mini-review. - Gerontology 60: 49-55, 2014.

Khanna-Chopra R., Srivalli B., Ahlawat Y.S.: Drought induces many forms of cysteine proteases not observed during natural senescence. - Biochem. Bioph. Res. Co. 255: 324-327, 1999.

Khanna-Chopra R.: Leaf senescence and abiotic stresses share reactive oxygen species-mediated chloroplast degradation. Protoplasma 249: 469-481, 2012.

Kim J.H., Woo H.R., Kim J. et al.: Trifurcate feed-forward regulation of age-dependent cell death involving mir164 in Arabidopsis. - Science 323: 1053-1057, 2009.

Kotchoni S.O., Larrimore K.E., Mukherjee M. et al:: Alterations in the endogenous ascorbic acid content affect flowering time in Arabidopsis. - Plant Physiol. 149: 803-815, 2009.

Leopold A.C.: Senescence in plant development: the death of plants or plant parts may be of positive ecological or physiological value. - Science 134: 1727-1732, 1961.

Lichtenthaler H.K.: Chlorophyll and carotenoids: Pigments of photosynthetic biomembranes. - Method. Enzymol. 148: 350-382, 1987.

Livak K.J., Schmittgen T.D.: Analysis of relative gene expression data using real-time quantitative PCR and the $2^{-\Delta \Delta \mathrm{CT}}$ method. Methods 25: 402-408, 2001.

Lohman K.N., Gan S., John M.C., Amasino R.M.: Molecular analysis of natural leaf senescence in Arabidopsis thaliana. Physiol. Plantarum 92: 322-328, 1994.

Luo P., Ning G., Wang Z. et al.: Disequilibrium of flavonol synthase and dihydroflavonol-4-reductase expression associated tightly to white vs. red color flower formation in plants. Front. Plant Sci. 6: 1257, 2016.

Manríquez D., El-Sharkawy I., Flores F.B. et al.: Two highly divergent alcohol dehydrogenases of melon exhibit fruit ripening-specific expression and distinct biochemical characteristics. - Plant Mol. Biol. 61: 675-685, 2006.

Mencuccini M., Munné-Bosch S.: Physiological and biochemical 
processes related to ageing and senescence in plants. In: Shefferson R.P., Jones O.R., Salguero-Gómez R. (ed.): The Evolution of Senescence in the Tree of Life. Pp. 257-283. Cambridge University Press, Cambridge 2017.

Millar A.H., Mittova V., Kiddle G. et al.: Control of ascorbate synthesis by respiration and its implications for stress responses. - Plant Physiol. 133: 443-447, 2003.

Navabpour S., Morris K., Allen R. et al.: Expression of senescence-enhanced genes in response to oxidative stress. J. Exp. Bot. 54: 2285-2292, 2003.

Naz H., Akram N.A., Ashraf M.: Impact of ascorbic acid on growth and some physiological attributes of cucumber (Cucumis sativus) plants under water-deficit conditions. Pak. J. Bot. 48: 877-883, 2016.

Noctor G., Foyer C.H.: Ascorbate and glutathione: keeping active oxygen under control. - Annu. Rev. Plant Biol. 49: 249-279, 1998 .

Ougham H., Hörtensteiner S., Armstead I. et al.: The control of chlorophyll catabolism and the status of yellowing as a biomarker of leaf senescence. - Plant Biol. 10: 4-14, 2008.

Oxborough K., Baker N.R.: Resolving chlorophyll $a$ fluorescence images of photosynthetic efficiency into photochemical and non-photochemical components - calculation of $\mathrm{q}_{\mathrm{P}}$ and $\mathrm{F}_{\mathrm{v}}{ }^{\prime} / \mathrm{F}_{\mathrm{m}}{ }^{\prime}$; without measuring $\mathrm{F}_{\mathrm{O}}{ }^{\prime}$. - Photosynth. Res. 54: 135142, 1997.

Peng C.L., Chen S.W., Lin Z.F., Lin G.Z.: Detection of antioxidative capacity in plants by scavenging organic free radical DPPH. - Prog. Biochem. Biophys. 27: 658-661, 2000. [In Chinese with English abstract]

Picton S., Barton S.L., Bouzayen M. et al.: Altered fruit ripening and leaf senescence in tomatoes expressing an antisense ethylene-forming enzyme transgene. - Plant J. 3: 469-481, 1993.

Pineau B., Layoune O., Danon A., De Paepe R.: L-galactono1,4-lactone dehydrogenase is required for the accumulation of plant respiratory complex I. - J. Biol. Chem. 283: 3250032505, 2008

Romero-Puertas M.C., Rodríguez-Serrano M., Corpas F.J. et al.: Cadmium-induced subcellular accumulation of $\mathrm{O}_{2}^{-{ }^{-}}$and $\mathrm{H}_{2} \mathrm{O}_{2}$ in pea leaves. - Plant Cell Environ. 27: 1122-1134, 2004.

Ruduś I., Sasiak M., Kępczyński J.: Regulation of ethylene biosynthesis at the level of 1-aminocyclopropane1-carboxylate oxidase (ACO) gene. - Acta Physiol. Plant. 35: 295-307, 2013.

Sade N., del Mar Rubio-Wilhelmi M., Umnajkitikorn K., Blumwald E.: Stress-induced senescence and plant tolerance to abiotic stress. - J. Exp. Bot. 69: 845-853, 2017.

Sarwat M., Naqvi A.R., Ahmad P. et al.: Phytohormones and microRNAs as sensors and regulators of leaf senescence: assigning macro roles to small molecules. - Biotechnol. Adv. 31: 1153-1171, 2013.

Schaller G.E., Bleecker A.B.: Ethylene-binding sites generated in yeast expressing the Arabidopsis ETR 1 gene. - Science 270: 1809-1811, 1995.

Shi H., Liu W., Yao Y. et al.: Alcohol dehydrogenase 1 (ADH1) confers both abiotic and biotic stress resistance in Arabidopsis. - Plant Sci. 262: 24-31, 2017.

Singh R.K., Sane V.A., Misra A. et al.: Differential expression of the mango alcohol dehydrogenase gene family during ripening. - Phytochemistry 71: 1485-1494, 2010.

Smart C.M.: Gene expression during leaf senescence. - New Phytol. 126: 419-448, 1994.

Stanford A., Bevan M., Northcote D.: Differential expression within a family of novel wound-induced genes in potato. Mol. Gen. Genet. 215: 200-208, 1989.

Szarka A., Bánhegyi G., Asard H.: The inter-relationship of ascorbate transport, metabolism and mitochondrial, plastidic respiration. - Antioxid. Redox Sign. 19: 1036-1044, 2013.

Tabata K., Ôba K., Suzuki K., Esaka M.: Generation and properties of ascorbic acid-deficient transgenic tobacco cells expressing antisense RNA for 1-galactono-1,4-lactone dehydrogenase. - Plant J. 27: 139-148, 2001.

Terzi R., Kalaycioglu E., Demiralay M. et al.: Exogenous ascorbic acid mitigates accumulation of abscisic acid, proline and polyamine under osmotic stress in maize leaves. - Acta Physiol. Plant. 37: 43, 2015.

Tokunaga T., Miyahara K., Tabata K., Esaka M.: Generation and properties of ascorbic acid-overproducing transgenic tobacco cells expressing sense RNA for L-galactono-1,4-lactone dehydrogenase. - Planta 220: 854-863, 2005.

van der Graaff E., Schwacke R., Schneider A. et al.: Transcription analysis of Arabidopsis membrane transporters and hormone pathways during developmental and induced leaf senescence.Plant Physiol. 141: 776-792, 2006.

Weaver L.M., Gan S., Quirino B., Amasino R.M.: A comparison of the expression patterns of several senescence-associated genes in response to stress and hormone treatment. - Plant Mol. Biol. 37: 455-469, 1998.

Wheeler G.L., Jones M.A., Smirnoff N.: The biosynthetic pathway of vitamin $\mathrm{C}$ in higher plants. - Nature 393: 365369, 1998.

Wojciechowska N., Sobieszczuk-Nowicka E., BagniewskaZadworna A.: Plant organ senescence - regulation by manifold pathways. - Plant Biol. 20: 167-181, 2018.

Woo H.R., Masclaux-Daubresse C., Lim P.O.: Plant senescence: how plants know when and how to die. - J. Exp. Bot. 69: 715-718, 2018.

Xu Z., Mahmood K., Rothstein S.J.: ROS induces anthocyanin production via late biosynthetic genes and anthocyanin deficiency confers the hypersensitivity to ROS-generating stresses in Arabidopsis. - Plant Cell Physiol. 58: 1364-1377, 2017.

Yoshida S.: Molecular regulation of leaf senescence. - Curr. Opin. Plant Biol. 6: 79-84, 2003.

Yu Y.W., Wang J., Li S.H. et al.: Ascorbic acid integrates the antagonistic modulation of ethylene and abscisic acid in the accumulation of reactive oxygen species. - Plant Physiol. 179: 1861-1875, 2019.

Zhang T.J., Chow W.S., Liu X.T. et al.: A magic red coat on the surface of young leaves: anthocyanins distributed in trichome layer protect Castanopsis fissa leaves from photoinhibition. Tree Physiol. 36: 1296-1306, 2016.

Zhang X.H., Zheng X.T., Sun B.Y. et al.: Over-expression of the CHS gene enhances resistance of Arabidopsis leaves to high light. - Environ. Exp. Bot. 154: 33-43, 2018.

(C) The authors. This is an open access article distributed under the terms of the Creative Commons BY-NC-ND Licence. 